\title{
Thyroid stimulating hormone (TSH) concentrations and menopausal status in women at the mid-life: SWAN
}

\author{
MaryFran Sowers*, Judy Luborskyt, Craig Perdue*, \\ Katy L. B. Araujoł, Marlene B. Goldman‡ and \\ Siobán D. Harlow* \\ *University of Michigan, Ann Arbor, MI, †Rush University, \\ Rush-Presbyterian-St Luke's Medical Center, Chicago, IL \\ and $\ddagger$ New England Research Institutes, Watertown, MA, \\ USA
}

(Received 21 March 2002; returned for revision 15 April 2002; finally revised 9 September 2002; accepted 4 October 2002)

\section{Summary}

OBJECTIVE We evaluated menopausal symptoms, menstrual cycle bleeding characteristics and reproductive hormones for their associations with thyroid stimulating hormone (TSH) concentrations in women at the mid-life from five ethnic groups.

METHODS This report is from the baseline evaluation of the Study of Women's Health Across the Nation (SWAN), a community-based multiethnic study of the natural history of the menopausal transition. Enrollees were 42-52 years old (pre- and early perimenopausal) African American, Caucasian, Chinese, Hispanic and Japanese women $(n=3242)$. Enrollees were interviewed about self-reported diagnosed hypo- and hyperthyroidism or thyroid treatment, menopausal symptoms and menstrual cycle bleeding characteristics. Serum was assayed for TSH, oestradiol, testosterone, FSH and SHBG.

RESULTS There were $6.2 \%$ of women with TSH > $5.0 \mathrm{mIU} / \mathrm{ml}$ and $3.2 \%$ with $\mathrm{TSH}<0.5 \mathrm{IU} / \mathrm{ml}$, cutpoints that have been used to encompass clinical and subclinical hypo- and hyperthyroidism, respectively. African American women had significantly lower mean TSH concentrations than Caucasian, Hispanic and Chinese women. Of the more than 15 menopause symptoms evaluated, only fearfulness was associated with having a TSH value $>5.0 \mathrm{mIU} / \mathrm{ml}(P<0.008)$ or $<0.5$ $\mathrm{mIU} / \mathrm{ml}(P<0.02)$. Women with TSH values outside the range of $0.5-5.0 \mathrm{mIU} / \mathrm{ml}$ were more likely to report

Correspondence: MaryFran Sowers, PhD, Department of Epidemiology, School of Public Health, University of Michigan, 109 S. Observatory, Ann Arbor, MI 48109-2029, USA. Tel.: 734936 3892;

Fax: 734998 8027; E-mail: mfsowers@umich.edu shorter or longer menstrual periods $(P=\mathbf{0 . 0 0 4}$ for both) than women within that range. FSH, SHBG, dehydroepiandrosterone sulphate (DHEA-S), testosterone, and oestradiol concentrations were not associated with TSH concentrations.

CONCLUSION In mid-aged women, there was a $9.6 \%$ prevalence of TSH values outside the euthyroid range of $0.5-5.0 \mathrm{mlU} / \mathrm{ml}$. Although TSH was associated with bleeding length and self-reported fearfulness, it was not associated with indicators of the menopausal transition, including menopausal stage defined by bleeding regularity, menopausal symptoms or reproductive hormone concentrations.

In women, reports of hypothyroidism prevalence have ranged from $0 \cdot 5 \%$ (Nolan et al., 1985) to $9 \cdot 3 \%$ (Vanderpump et al., 1995) while the reported prevalence of hyperthyroidism has ranged from $0 \cdot 2 \%$ (Nolan et al., 1985) to $3 \cdot 9 \%$ (Tunbridge et al., 1977; Petersen et al., 1991; Konno et al., 1993; Vanderpump et al., 1995; Canaris et al., 2000), with some of the variation associated with different disease definitions. There are few studies of thyroid status and the menopause transition, although the prevalence of thyroid disease, particularly hypothyroidism, increases with advancing age (Falkenberg et al., 1983; Petersen et al., 1991; Vanderpump et al., 1995; Canaris et al., 2000). Furthermore, no published studies compare thyroid stimulating hormone (TSH) concentrations in multiple race/ethnic groups. The only study that includes African American women focused on disease treatment in older women (Bagchi et al., 1990).

Thyroid status may contribute to the variation in symptom frequency and intensity as well as in bleeding patterns during the menopausal transition (Massoudi et al., 1995). It has long been recognized clinically that thyroid disease is associated with menstrual cycle disturbances (Stoffer, 1982; Wilson \& Foster, 1985; Koutras, 1995; Doufas \& Mastorakos, 2000) although the evidence for a link with hypothyroidism is controversial (Krassas et al., 1999; Prentice, 1999). Joshi et al. (1993) have found that menstrual irregularities may precede other clinical features of thyroid dysfunction and argue that thyroid function should be evaluated in perimenopausal women with menstrual irregularity.

Hyper- and hypothyroid states may cause marked alterations in steroid metabolism. Hyperthyroidism has been associated with decreased free testosterone concentration, and, in some instances, a decrease in oestradiol, as well as a marked increase in SHBG 
(Longcope et al., 1990; Ford et al., 1992; Koutras, 1995; Brenta et al., 1999). FSH concentrations may also be increased. In contrast, hypothyroidism results in decreased prevalence of 5-alpha metabolites of androgens, a decrease in the 2-hydroxylation of oestrone and an increase in peripheral aromatization of androstenedione to oestrone (Longcope et al., 1990). Thus, in reproductive endocrine studies, altered thyroid status could potentially contribute to variations in hormone levels commonly associated with the menopause transition.

The Study of Women's Health Across the Nation (SWAN) is a community-based study of the natural history of the menopausal transition in a multiethnic population. SWAN provides a unique opportunity to address questions about thyroid status because it was developed expressly to distinguish the endocrine, physical and psychosocial characteristics of the menopausal transition. This paper identifies the prevalence of self-reported diagnosis of hypo- and hyperthyroidism and treatment among women aged 42-52 years. It also evaluates serum TSH concentration and its association with reproductive hormone concentrations, menopausal symptoms and menstrual bleeding characteristics in the pre- and early perimenopause.

\section{Methods and materials}

\section{Population}

The SWAN is a prospective, multiethnic, multidisciplinary study of the natural history of the menopausal transition in 3302 women. SWAN study sites are located in seven US locations: Boston, Chicago, the Detroit area, Los Angeles, Newark, Pittsburgh and Oakland, California. A two-stage recruitment process was used to recruit women. First, in 1995-97, a 15-minute survey was used to collect limited health-related data and compile a listing of women who could be sampled for the longitudinal study. Women eligible for the survey were aged $40-55$ years, spoke English or one of the other study languages (Spanish, Japanese, Cantonese) and were members of the target racial/ethnic group identified by each site. During the second stage, each clinical centre recruited community-based samples of approximately 450 women from their local first-stage sample. These women were 42-52 years, pre- or early perimenopausal (defined as having had at least one menstrual period in the previous 3 months), and not using exogenous hormone preparations affecting ovarian function. Recruitment was stratified at each site to achieve a designated proportion of non-Hispanic Caucasian women and a minority group (African American, Chinese, Hispanic or Japanese). Additional information about the eligibility criteria, sampling frames and characteristics of participants has been published previously (Sowers et al., 2000). All study activities were undertaken with approval of an appropriate Institutional Review Board.

\section{Measures}

A common protocol was used by the seven clinical sites. Selfreported menopausal status was classified as perimenopausal, indicating menses had occurred in the past 3 months but had become less predictable, or premenopausal, indicating menses had occurred in the past 3 months with no decreased predictability. Age, smoking behaviour and ethnicity were also self-reported. Primary race/ethnicity was self-defined.

Women reported how frequently they experienced each of 15 menopause symptoms including vasomotor symptoms and forgetfulness in the 2 weeks prior to interview, with responses ranging from 1 (not at all) to 5 (daily) for each item (Neugarten \& Kraines, 1965; Avis et al., 1993; Matthews et al., 1993). Depressive symptomatology was assessed with the Center for Epidemiological Studies Depression (CES-D) scale, a well-validated 20-item scale with four-level responses indicating frequency of experiencing each symptom in the past week (Radloff, 1977). It has been shown to correlate well with other depressive symptom questionnaires and with diagnostic interviews that assess severity of depression (Fechner-Bates et al., 1994).

Women were asked if they had been diagnosed as having an underactive thyroid or overactive thyroid and were asked to report all medications used, including those for thyroid disease.

\section{Assays}

A blood sample was taken from enrollees following an 8-hour fast during days 2-7 of the follicular phase of the menstrual cycle. Hormone assays were conducted in the SWAN Endocrine Laboratory at the University of Michigan using an ACS-180 automated analyser (Bayer Diagnostics Corp., 115 Norwood Park South, Norwood, MA 02062, USA). TSH concentration was assessed using the commercial ACS:180 TSH assay (Bayer Diagnostics), which is a two-site sandwich chemiluminescent assay using a DMAE-labelled monoclonal mouse antibody and a polyclonal sheep antibody coupled to paramagnetic particles. Inter- and intra-assay coefficients of variation (CVs) were $9.0 \%$ and $1.9 \%$, respectively. The cutpoints of $<0.5 \mathrm{mIU} / \mathrm{ml}$ and $>5.0 \mathrm{mIU} / \mathrm{ml}$ were used to establish boundaries for being euthyroid (Wilson \& Foster, 1985). Table 1 shows the frequency of TSH values outside these boundaries that may be related to various definitions of subclinical and clinical disease. No additional markers of thyroid status, including T3, T4 or autoantibodies, were assayed.

Serum oestradiol concentrations were measured with a modified, off-line ACS:180 ( $\left.\mathrm{E}_{2}-6\right)$ immunoassay. Inter- and intraassay CVs averaged $10 \cdot 6 \%$ and $6 \cdot 4 \%$, respectively, over the assay range. Serum FSH concentrations were measured with a two-site chemiluminometric immunoassay that uses constant amounts of two monoclonal antibodies (provided by Bayer Diagnostics). 
Table 1 Distribution of TSH concentrations in pre- and perimenopausal women, aged $42-52$ years: SWAN

\begin{tabular}{lccccc}
\hline & \multicolumn{2}{l}{ All women } & & \multicolumn{2}{c}{ Untreated women } \\
\cline { 2 - 3 } \cline { 6 - 6 } $\begin{array}{l}\text { TSH }(\mathrm{mIU} / \mathrm{ml}) \\
\text { groupings }\end{array}$ & Frequency & Percent & & Frequency & Percent \\
\hline$<0 \cdot 1$ & 38 & $1 \cdot 17$ & & 17 & $0 \cdot 55$ \\
$0 \cdot 1-0 \cdot 29$ & 32 & $0 \cdot 99$ & & 41 & $0 \cdot 78$ \\
$0 \cdot 3-0 \cdot 49$ & 34 & $1 \cdot 05$ & & 72 & $1 \cdot 00$ \\
$0 \cdot 5-5 \cdot 0$ & 2937 & $90 \cdot 59$ & & 2852 & $92 \cdot 39$ \\
$5 \cdot 01-10$ & 154 & $4 \cdot 75$ & & 127 & $4 \cdot 11$ \\
$10 \cdot 01-15 \cdot 0$ & 28 & $0 \cdot 86$ & & 24 & $0 \cdot 78$ \\
$15 \cdot 01-20 \cdot 0$ & 9 & $0 \cdot 28$ & & 6 & $0 \cdot 19$ \\
$>20^{*}$ & 10 & $0 \cdot 31$ & & 6 & $0 \cdot 19$ \\
\hline
\end{tabular}

*Excludes five women omitted from analysis because of extreme, but uncertain, values.

Each antibody is directed to different regions on the beta subunit (one coupled to paramagnetic particles and the other labelled with DMAE) with specificity for intact FSH. Inter- and intraassay $\mathrm{CVs}$ were $12 \cdot 0 \%$ and $6 \cdot 0 \%$, respectively. Testosterone concentrations were evaluated with the ACS: 180 total testosterone assay modified to increase precision in the lower ranges. The resulting assay includes competitive binding of a DMAElabelled testosterone derivative to a rabbit polyclonal antitestosterone antibody premixed with monoclonal antirabbit IgG antibody immobilized on the solid-phase paramagnetic particles. Inter- and intra-assay CVs were $10 \cdot 2 \%$ and $5 \cdot 1 \%$, respectively, for this modified assay. The free androgen index (FAI) was derived to address the activity of the nonbound androgen: $\mathrm{FAI}=(100 \mathrm{~T} / 28 \cdot 84 \times \mathrm{SHBG})$. The free oestradiol index $(\mathrm{FEI})$ was derived using FEI $=(100 \times \mathrm{E} 2 / 272 \cdot 11 \times \mathrm{SHBG})$, consistent with the approach of Van den Beld et al. (2000). The de novo two-site chemiluminescent assay for SHBG involved competitive binding of DMAE-labelled SHBG to a commercially available rabbit anti-SHBG antibody and a solid phase of goat antirabbit IgG conjugated to paramagnetic particles. Inter- and intra-assay CVs were $9 \cdot 9 \%$ and $6 \cdot 1 \%$, respectively. The dehydroepiandrosterone sulphate (DHEA-S) assay was developed on-site using rabbit anti-DHEA-S antibodies, with an LLD of $1.52 \mu \mathrm{g} / \mathrm{dl}$.

\section{Data analysis}

Of the 3302 women, there were the following exclusions: 16 women had no TSH values, five had very high TSH values with uncertain data quality, and 46 did not respond to questions concerning thyroid status or thyroid medication, including seven women who failed to answer either question. Data management and analysis were conducted with SAS v.6.12 (SAS Institute, Cary, NC, USA).
Univariate statistics were calculated for continuous variables including TSH, other hormones, body mass index (BMI) and age. For purposes of multivariable analyses, a natural $\log$ (of FSH and reproductive hormones) or square root (for SHBG and TSH) transformation was applied to address skewness or to satisfy the modelling assumptions such as normally distributed residuals. A kappa statistic was used to show agreement between being treated for thyroid disease and having a TSH in the euthyroid range.

We correlated TSH and reproductive hormones and reported the partial correlation coefficients following adjustment for important covariates. Important covariates were age, race/ethnicity, clinical site and smoking behaviour. All analyses were performed both with and without women who reported taking thyroid medication. Adjustment for day of cycle had no impact on the observed associations.

The least squared mean (LSmean) TSH concentrations for pre- and perimenopausal women was calculated using analysis of covariance within the SAS PROC GLM procedure. Multiple variable logistic regression was used to evaluate the association of TSH concentrations as a continuous independent variable and menopause status as the dichotomous dependent variable, after including appropriate covariates.

Contingency table analyses using the $\chi^{2}$-test statistic of homogeneity were used to relate menstrual characteristics, premenstrual and menopausal symptoms with TSH categorized as $<0.5 \mathrm{mIU} / \mathrm{ml}, 0 \cdot 5-5.0 \mathrm{mIU} / \mathrm{ml}$ or $>5.0 \mathrm{mIU} / \mathrm{ml}$. Ordinal logistic regression was used to relate multilevel menopause symptoms or bleeding characteristics to TSH concentrations (continuous) or TSH categories as independent variables. For example, this approach was used when bleeding flow lengths, reported at multiple levels (1-2 days, 3-7 days and $>7$ days in the 2 weeks prior to interview), were associated with TSH categories as the independent variable. The proportionality assumption of ordinal logistic regression was met. Model fit, including appropriateness of transformations, was assessed graphically and using residual analyses.

\section{Results}

The mean and median TSH concentrations in these pre- and perimenopausal women, aged 42-52 years, were $2 \cdot 4(2 \cdot 2 \mathrm{SD})$ and

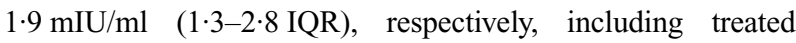
women. When women treated with thyroid medication were excluded, the mean (SD) and median (IQR) TSH concentrations were $2.3(1.9)$ and $1.89(1.33-2.77) \mathrm{mIU} / \mathrm{ml}$, respectively. There were $3 \cdot 2 \%(n=104)$ of women with TSH values less than $0.5 \mathrm{mIU} / \mathrm{ml}$ and $6 \cdot 2 \%(n=201)$ of women with $\mathrm{TSH}$ values greater than $5.0 \mathrm{mIU} / \mathrm{ml}$ (see Table 2).

By self-report, 7.6\% $(n=248)$ of women characterized themselves as having an underactive thyroid compared to $3 \cdot 6 \%$ ( $n=117)$ of women who characterized themselves as having an 
Table 2 Thyroid status characteristics based on TSH concentrations in pre- and perimenopausal women, aged $42-52$ years, including mean \pm SD and median (IQR)

\begin{tabular}{|c|c|c|c|}
\hline Characteristic & $\mathrm{TSH}<0.5 \mathrm{mIU} / \mathrm{ml}$ & $0 \cdot 5-5 \cdot 0 \mathrm{mIU} / \mathrm{ml}$ (euthyroid) & $\mathrm{TSH}>5.0 \mathrm{mIU} / \mathrm{ml}$ \\
\hline \multicolumn{4}{|l|}{ All women $(n=3242)$} \\
\hline Mean TSH (SD) (mIU/ml) & $0 \cdot 2(0 \cdot 16)$ & $2 \cdot 0(0 \cdot 9)$ & $8 \cdot 7(4 \cdot 6)$ \\
\hline Median TSH (IQR) & $0 \cdot 18(0 \cdot 03-0 \cdot 3)$ & $1 \cdot 8(1 \cdot 33-2 \cdot 62)$ & $6 \cdot 7(5 \cdot 9-9 \cdot 5)$ \\
\hline \multicolumn{4}{|l|}{ Untreated women $(n=3087)$} \\
\hline Mean TSH (SD) (mIU/ml) & $0 \cdot 24(0 \cdot 15)$ & $2.05(0.9)$ & $8 \cdot 36(4 \cdot 2)$ \\
\hline Median TSH (IQR) & $0 \cdot 2(0 \cdot 1-0 \cdot 4)$ & $1 \cdot 8(1 \cdot 3-2 \cdot 6)$ & $6 \cdot 7(5 \cdot 9-9 \cdot 2)$ \\
\hline Total number of women & $104(3 \cdot 2 \%)$ & $2937(90 \cdot 6 \%)$ & $201(6 \cdot 2 \%)$ \\
\hline
\end{tabular}

$\mathrm{SD}$, standard deviation; IQR, interquartile range.

Table 3 The frequency (number and percent) of self-reported thyroid status and thyroid medication use according to TSH cutpoints in pre- and perimenopausal women

\begin{tabular}{|c|c|c|c|c|}
\hline Characteristic & $\mathrm{TSH}<0.5 \mathrm{mIU} / \mathrm{ml}$ & $0 \cdot 5-5 \cdot 0 \mathrm{mIU} / \mathrm{ml}$ (euthyroid) & $\mathrm{TSH}>5.0 \mathrm{mIU} / \mathrm{ml}$ & kappa* \\
\hline \multicolumn{5}{|l|}{ Self-report thyroid state } \\
\hline Underactive thyroid & $30(28 \cdot 8 \%)$ & $165(5 \cdot 6 \%)$ & $53(26 \cdot 4 \%)$ & $0 \cdot 09$ \\
\hline Euthyroid & $59(56 \cdot 7 \%)$ & $2682(91 \%)$ & $134(66 \cdot 7 \%)$ & \\
\hline Overactive thyroid & $15(14 \cdot 4 \%)$ & $88(3 \cdot 0 \%)$ & $14(7 \cdot 0 \%)$ & \\
\hline \multicolumn{5}{|l|}{ Using thyroid medication } \\
\hline For underactive thyroid & $26(22 \cdot 0 \%)$ & $62(51 \cdot 6 \%)$ & $32(26 \cdot 6 \%)$ & $0 \cdot 21$ \\
\hline For overactive thyroid & $6(17 \cdot 1 \%)$ & $23(65 \cdot 7 \%)$ & $6(17 \cdot 1 \%)$ & \\
\hline
\end{tabular}

*Values of kappa $<0 \cdot 40$ represent poor agreement between self-reported status and laboratory-defined status.

Table 4 Frequency (number and percent) of women in TSH categories used as a proxy for thyroid status, according to race/ethnicity designation

\begin{tabular}{lrrr}
\hline & & \multicolumn{1}{l}{$\begin{array}{l}0 \cdot 5-5 \cdot 0 \mathrm{mIU} / \mathrm{ml} \\
\text { (euthyroid) }\end{array}$} & TSH $>5 \cdot 0 \mathrm{mIU} / \mathrm{ml}$ \\
\hline All women & & & \\
$\quad$ African American & $40(4 \cdot 3 \%)$ & $844(92 \cdot 0 \%)$ & $33(3 \cdot 6 \%)$ \\
Hispanic & $5(1 \cdot 7 \%)$ & $261(91 \cdot 9 \%)$ & $18(6 \cdot 3 \%)$ \\
Chinese & $8(3 \cdot 3 \%)$ & $219(90 \cdot 1 \%)$ & $16(6 \cdot 6 \%)$ \\
Japanese & $10(3 \cdot 6 \%)$ & $264(94 \cdot 9 \%)$ & $4(1 \cdot 4 \%)$ \\
Caucasian & $41(2 \cdot 7 \%)$ & $1349(88 \cdot 7 \%)$ & $130(8 \cdot 5 \%)$ \\
Untreated women & & & \\
African American & $30(3 \cdot 4 \%)$ & $822(93 \cdot 9 \%)$ & $23(2 \cdot 6 \%)$ \\
Hispanic & $4(1 \cdot 4 \%)$ & $255(92 \cdot 4 \%)$ & $17(6 \cdot 2 \%)$ \\
Chinese & $6(2 \cdot 6 \%)$ & $210(92 \cdot 1 \%)$ & $12(5 \cdot 3 \%)$ \\
Japanese & $8(2 \cdot 9 \%)$ & $262(96 \cdot 0 \%)$ & $3(1 \cdot 1 \%)$ \\
Caucasian & $24(1 \cdot 7 \%)$ & $1303(90 \cdot 8 \%)$ & $108(7 \cdot 5 \%)$ \\
\hline
\end{tabular}

overactive thyroid (see Table 3 ). Of the $4 \cdot 7 \%$ of women who reported thyroid medication use, $58 \%$ (90 out of 155 ) had TSH concentrations within the euthyroid range. Of those treated for an underactive thyroid, $48 \%$ (58 out of 120 ) had TSH values outside the normal range. Of those treated for an overactive thyroid, $34 \%$ (12 out of 35 ) had TSH values outside the normal range.
As shown in Table 4, African American women were proportionately more likely to have TSH values less than $0.5 \mathrm{mIU} / \mathrm{ml}$ while Caucasian, Hispanic and Chinese women were more likely to have values greater than $5 \cdot 0 \mathrm{mIU} / \mathrm{ml}(P<0 \cdot 0001)$. Figure 1 shows the mean absolute TSH concentrations as well as the least squared means of the transformed TSH concentrations by race/ 


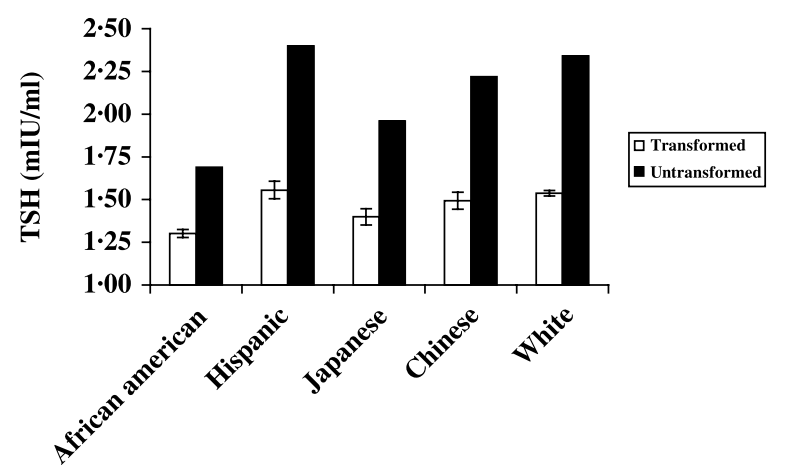

Race/Ethnicity

Fig. 1 The LSmeans for TSH (open bars, transformed; solid bars, untransformed) by self-reported race/ethnicity designation, following adjustment for age, BMI, clinical site and smoking behaviour.

ethnic groups. African American women had a significantly lower LSmean TSH concentration than all groups except for Japanese women. In turn, the LSmean TSH concentrations of Japanese women were significantly lower than TSH concentrations of Caucasian women but not of the Chinese or Hispanic women.

TSH concentrations increased with age even among women in this narrow age range of $42-52$ years $(P<0 \cdot 04)$. For each 5year increase in age, there was a $3.5 \%$ increase in TSH concentrations. BMI and smoking classification were not related to the TSH concentrations after adjusting for age, clinical site and race/ ethnicity (data not shown).

\section{TSH and menopause-related symptoms}

Two symptoms were associated with TSH concentrations. Frequency of feeling fearful in the 2 weeks prior to interview was associated with TSH concentrations $(P<0 \cdot 008)$. Women who reported feeling fearful were disproportionately represented in the group with TSH $<0.5 \mathrm{mIU} / \mathrm{ml}(P<0.02)$. Women who selfreported less sexual interest had a slightly lower adjusted mean TSH concentration than women who maintained their level of sexual interest ( $2.03 v s .2 \cdot 16 \mathrm{mIU} / \mathrm{ml} ; P<0 \cdot 03)$.

TSH concentrations were not associated with self-reported sleep disturbances, stiffness, cold sweats, hot flashes, night sweats, vaginal dryness, urinary incontinence, irritability, feeling blue, tense or nervous, having mood changes, forgetfulness or heart palpitations in the 2 weeks prior to interview (data not shown). Women classified as having depressive symptomatology (CES-D score greater than 15) had a mean TSH of 2.07 vs. $2 \cdot 13 \mathrm{mIU} / \mathrm{ml}$ in women who were not depressed $(P<0 \cdot 40)$.

\section{Patterns of menstrual bleeding and reproductive hormones}

TSH concentrations were modestly associated with usual length of menstrual flow in the year prior to interview (see Table 5). Women outside the TSH range of $0.5-5.0 \mathrm{mIU} / \mathrm{ml}$ were more likely to report shorter or longer menstrual periods $(P=0.004)$. The adjusted TSH means were $1 \cdot 98,2 \cdot 11,2.34$ and $3.96 \mathrm{mIU} /$ $\mathrm{ml}$ for flows lasting 1-2 days, 3-7 days, more than 7 days, and 'don't know', respectively $(P<0.02)$. These results remained constant when treated women were excluded.

TSH concentrations were not significantly associated with serum concentrations of FSH $(r=-0.01, P<0.41)$, SHBG $(r=-0.01, P<0 \cdot 40)$, DHEA-S $(r=-0.0005, P<0 \cdot 77)$, total testosterone $(r=0.02, \quad P<0.31)$ and oestradiol $(r=0.02$, $P<0 \cdot 27$ ), nor with their related SHBG-indices, FAI and FEI, even after adjustment for age, day in cycle, race/ethnicity, site and smoking behaviour.

\section{Discussion}

In these women, aged $42-52$ years, $9 \cdot 4 \%$ had TSH values outside the range of $0.5-5.0 \mathrm{mIU} / \mathrm{ml}$. Almost half of the women who reported being treated with thyroid medication did not have a TSH in the euthyroid range, consistent with other studies (Faughnan et al., 1995).

There was no significant difference in TSH concentrations among SWAN enrollees classified as premenopausal $v s$. early perimenopausal. While this is consistent with the findings from Massoudi et al. (1997), it is unlike two studies that evaluated older women (Ballinger et al., 1987; de Aloysio et al., 1996). Because SWAN is a longitudinal study, ultimately we will be able to evaluate the impact of each stage of the menopause transition on TSH and help to resolve questions regarding the impact of age $v s$. menopause status on thyroid status.

We observed no association of TSH with reproductive hormone concentrations, including oestradiol, although it has been

\begin{tabular}{lcccc}
\hline $\begin{array}{l}\text { Duration of the } \\
\text { menstrual flow }\end{array}$ & TSH $<0.5 \mathrm{mIU} / \mathrm{ml}$ & $\begin{array}{l}0.5-5 \cdot 0 \mathrm{mIU} / \mathrm{ml} \\
\text { (euthyroid) }\end{array}$ & $\mathrm{TSH}>5.0 \mathrm{mIU} / \mathrm{ml}$ & $P$-value of $\chi^{2}$ \\
\hline Usual flow length & & & 0.004 \\
$1-2$ days & $6(5 \cdot 7 \%)$ & $57(1.9 \%)$ & $6(2.9 \%)$ & \\
$3-7$ days & $89(85.5 \%)$ & $2718(92.5 \%)$ & $173(86.0 \%)$ & \\
$>7$ days & $8(7.7 \%)$ & $158(5 \cdot 3 \%)$ & $22(10.9 \%)$ & \\
\hline
\end{tabular}

Table 5 The frequency of usual menstrual flow length according to low, normal and high TSH concentrations 
reported that oestradiol concentrations increase TSH concentrations by antagonizing the feedback inhibition of TSH synthesis by T3 (Yarwood et al., 1993). Overlie et al. (1999) reported significantly higher TSH concentrations in the luteal phase compared with the follicular phase (data not given), although others have reported that TSH concentrations did not vary according to menstrual phase (Sawin et al., 1978). In SWAN, more than 85\% of blood draws were completed in days 2-7 of the follicular phase, the time period where there is less cyclic variation, avoiding potential misinterpretation of information. However, important differences may occur in the luteal phase and this could not be assessed.

We observed an association between the length of menstrual flow in the previous year and TSH concentrations. Because women were recruited to SWAN based on their menstrual characteristics, it was not possible to evaluate the association between TSH concentrations and either oligo- or amenorrhoea. Women with $\mathrm{TSH}>5.0 \mathrm{mIU} / \mathrm{ml}$ were twice as likely to report having menstrual bleeding lasting at least 8 days than were euthyroid women. Although several case reports suggest an association between menstrual dysfunction and thyroid status (Wilansky \& Greisman, 1989; Higham \& Shaw, 1992; Joshi et al., 1993; Massoudi et al., 1997), others have found no association of TSH, T4 and T3 levels with regular and irregular cycles (Krassas et al., 1999).

While there was no measure of anxiety in this study, feeling fearful was associated with TSH concentrations. Psychiatric symptoms, especially anxiety, are commonly reported prior to treatment of hyperthyroidism and exclusion of hyperthyroidism is recommended prior to making a psychiatric diagnosis (Kathol \& Delahunt, 1986; Stern et al., 1996). Some studies suggest that elevated anxiety persists in patients with Graves' disease (Paschke et al., 1990; Harsch et al., 1992) or that panic disorder precedes the onset of hypothyroidism (Matsubayashi et al., 1996). We found no association of depressed mood with TSH concentration, corroborating another report that depression was not significantly associated with thyroid status (Ballinger et al., 1987).

There were significant racial/ethnic differences in mean TSH concentrations in this sample with significantly lower mean TSH concentrations among African Americans and Japanese women. There is a paucity of literature on racial/ethnic variation in TSH levels but our results are consistent with the sparse literature. In two studies, Blacks had significantly lower levels of TSH and thyroid autoantibodies compared to Caucasians (American Psychiatric Association, 1987; Schectman et al., 1991) and a third study found that Hispanics had higher levels of thyroid autoantibodies compared to Blacks (Bowry et al., 1984). The importance of these ethnic variations is unknown, but may be related to ethnic variations in the prevalence of some autoimmune diseases or lifestyle factors that could include difference in food containing iodine.
While SWAN is uniquely positioned to characterize the menopause transition and thyroid status in a large community-based population, this report of the baseline cross-sectional data has limitations. SWAN is a study of the natural menopause whose eligibility was based on the presence of menstrual bleeding, thereby precluding the inclusion of women with hysterectomy, premature menopause, or highly variable bleeding, all conditions that have been related to thyroid status. Second, the data presented cannot be interpreted as representative of the entire transition. Continued evaluation of TSH concentrations in SWAN enrollees will allow us to relate baseline and subsequent thyroid status to the progression of menopause characteristics including symptoms and bleeding patterns. Third, TSH concentrations are only proxy measures. Although TSH has been widely used to evaluate populations from a screening perspective, measurement of T3 and T4, thyroid autoantibodies, or TSH alpha and beta subunits, would be required to more definitively define thyroid status. Fourth, in common with other glycoprotein hormones, TSH appears to have some episodic and circadian variation. This variability was addressed, in part, by employing phlebotomy protocols whereby blood was drawn in a fasting state in the morning (usually before $1100 \mathrm{~h}$ ) and in days 2-7 of the menstrual cycle (Kasim \& Bessman, 1984; Wilson \& Foster, 1985; Samuels et al., 1990). Finally, this report used TSH values of $0 \cdot 5-5 \cdot 0 \mathrm{mIU} / \mathrm{ml}$ as indicative of the normal range with the recognition that values outside that range were much more likely to encompass both clinical and subclinical disease. This was done with the understanding that additional data, such as T3/ T4 values and antibodies, were not available to specifically characterize thyroid status and that, in the absence of such additional supporting information, an alternative nosology would be open to challenge.

In summary, despite a relatively high prevalence $(9 \cdot 6 \%)$ of impaired thyroid status, there was little association with measures of the earliest stage of the menopause transition. Although TSH was associated with bleeding length and self-reported fearfulness, it was not associated with other measures thought to characterize menopausal symptoms or with reproductive hormone concentrations. Nonetheless, the marked frequency with which TSH values were outside the normal range is consistent with the recommendations that screening for thyroid status would be cost-effective (Danese et al., 1996). However, based on these findings, any move towards screening should not be predicated on women reporting symptoms associated with the menopausal transition or having FSH values thought to be indicative of the menopausal transition.

\section{Acknowledgements}

The Study of Women's Health Across the Nation (SWAN) was funded by the National Institute on Aging, the National Institute of Nursing Research and the Office of Research on Women's Health of the National Institutes of Health. Supplemental funding 
from National Institute of Mental Health, the National Institute on Child Health and Human Development, the National Center on Complementary and Alternative Medicine, the Office of Minority Health, and the Office of AIDS Research is also gratefully acknowledged.

Clinical Centers: University of Michigan, Ann Arbor, MI (U01 NR04061, MaryFran Sowers, PI); Massachusetts General Hospital, Boston, MA (U01 AG12531, Robert Neer/Joel Finkelstein, PI); Rush University, Rush-Presbyterian-St. Luke's Medical Center, Chicago, IL (U01 AG12505, Lynda Powell, PI); University of California/Kaiser, Davis, CA (U01 AG12554, Ellen Gold, PI); University of California, Los Angeles, CA (U01 AG12539, Gail Greendale PI); University of Medicine and Dentistry-New Jersey Medical School, Newark, NJ (U01 AG12535, Gerson Weiss, PI); and, the University of Pittsburgh, Pittsburgh, PA (U01 AG12546, Karen Matthews, PI).

Laboratory: University of Michigan, Ann Arbor, MI (U01 AG12495, Daniel McConnell, PI) and Medical Research Laboratories (MRL), Highland Heights, KY (subcontract of U01 AG12553, Evan Stein, Director).

Coordinating Center: University of Pittsburgh (Kim SuttonTyrrell, PI).

Project Officers: Taylor Harden, Carole Hudgings, Marcia Ory, Sherry Sherman.

Steering Committee Chair: Jennifer L. Kelsey.

We thank the study staff at each site and all of the women who participated in SWAN.

\section{References}

American Psychiatric Association (1987) Diagnostic and Statistical Manual of Mental Disorders, 3rd edn (revised). American Psychiatric Association, Washington, DC.

Bagchi, N., Brown, T. \& Parish, R. (1990) Thyroid dysfunction in adults over age 55 years: a study in an urban US community. Archives of Internal Medicine, 150, 785-787

Danese, M.D., Powe, N.R., Sawin, C.T. \& Ladenson, P.W. (1996) Screening for mild thyroid failure at the periodic health examination: a decision and cost-effectiveness analysis. Journal of the American Medical Association, 276, 285-292.

de Aloysio, D., Altieri, P., Penacchinioni, P., Mauloni, M. \& Bottiglioni, F. (1996) Premenopause-dependent changes. Gynecologic and Obstetric Investigation, 42, 120-127.

Avis, N.E., Kaufert, P.A., Lock, M., McKinlay, S.M. \& Vass, K. (1993) The evolution of menopausal symptoms. Bailliere's Clinical Endocrinology and Metabolism, 7, 17-32.

Ballinger, C.B., Browning, M.C.K. \& Smith, A.H.W. (1987) Hormone profiles and psychological symptoms in peri-menopausal women. Maturitas, 9, 235-251.

Bowry, T.R., Muturi, I.L., Radia, R. \& Gitau, W. (1984) Autoantibody profile in thyroid diseases in black Kenyans. Journal of Clinical and Laboratory Immunology, 15, 133-136.

Brenta, G., Schnitman, M., Gurfinkiel, M., Damilano, S., Pierini, A., Sinay, I. \& Pisarev, M.A. (1999) Variations of sex hormone-binding globulin in thyroid dysfunction. Thyroid, 9, 273-277.
Canaris, G., Manowitz, N., Mayor, G. \& Ridgeway, E. (2000) The Colorado Thyroid Disease Prevalence Study. Archives of Internal Medicine, 160, 526-534.

Doufas, A.G. \& Mastorakos, G. (2000) The hypothalamic-pituitary axis and female reproductive system. Annals of the New York Academy of Sciences, 900, 65-76.

Falkenberg, M., Bertil, K. \& Noor, A. (1983) Screening of an elderly female population for hypo- and hyperthyroidism by use of a thyroid hormone panel. Acta Medica Scandinavica, 214, 361-365.

Faughnan, M., Lepage, R., Fugere, P., Bissonnette, F., Brossard, J.H. \& D'Amour, P. (1995) Screening for thyroid disease at the menopausal clinic. Clinical and Investigative Medicine, 18, 11-18.

Fechner-Bates, S., Coyne, J.C. \& Schwenk, T.L. (1994) The relationship of self-reported distress to depressive disorders and other psychopathology. Journal of Consulting and Clinical Psychology, 62, $550-559$.

Ford, M.C., Cooke, R.R., Keightley, E.A. \& Feek, C.M. (1992) Serum levels of free and bound testosterone in hyperthyroidism. Clinical Endocrinology, 36, 187-192.

Harsch, I., Paschke, R. \& Usadel, K.H. (1992) The possible etiological role of psychological disturbances in Graves' disease. Acta Medica Austriaca, 19 (Suppl. 1), 62-65.

Higham, J.M. \& Shaw, R.W. (1992) The effect of thyroxine replacement on menstrual blood loss in a hypothyroid patient. British Journal of Obstetrics and Gynaecology, 99, 695-696.

Joshi, J.V., Bhandarkar, S.D., Chadha, M., Balaiah, D. \& Shah, R. (1993) Menstrual irregularities and lactation failure may precede thyroid dysfunction or goiter. Journal of Postgraduate Medicine, 39, 137-141.

Kasim, S. \& Bessman, A. (1984) Thyroid autoimmunity in type 2 (non-insulin-dependent) diabetic patients of Caucasoid, Black and Mexican origin. Diabetologia, 27, 59-61.

Kathol, R.G. \& Delahunt, J.W. (1986) The relationship of anxiety and depression to symptoms of hyperthyroidism using operational criteria. General Hospital Psychiatry, 8, 23-28.

Konno, N., Yuri, K., Taguchi, H., Miura, K., Taguchi, S., Hagiwara, K. \& Murakami, S. (1993) Screening for thyroid disease in an iodine sufficient area with sensitive thyrotropin assays and serum thyroid autoantibody and urinary iodide determinations. Clinical Endocrinology, 38, 273-281.

Koutras, D.A. (1995) Disturbances of menstruation in thyroid disease. Annals of the New York Academy of Sciences, 816, 280-284.

Krassas, G.E., Pontikides, N., Kaltsas, T., Papadopoulou, P., Paunkovic, J., Paunkovic, N. \& Duntas, L.H. (1999) Disturbances of menstruation in hypothyroidism. Clinical Endocrinology, 50, 655-659.

Longcope, C., Abend, S., Braverman, L.E. \& Emerson, C.H. (1990) Androstenedione and estrone dynamics in hypothyroid women. Journal of Clinical Endocrinology and Metabolism, 70, 903-907.

Massoudi, M.S., Meilahn, E.N., Orchard, T.J., Foley, T.P. Jr, Kuller, L.H., Costantino, J.P. \& Buhari, A.M. (1995) Prevalence of thyroid antibodies among healthy middle-aged women. Findings from the Thyroid Study in Healthy Women. Annals of Epidemiology, 5, 229-233.

Massoudi, M.S., Meilahn, E.N., Orchard, T.J., Foley, T.P. Jr, Kuller, L.H., Costantino, J.P. \& Buhari, A.M. (1997) Thyroid function and perimenopausal lipid and weight changes: the Thyroid Study in Healthy Women (TSH-W). Journal of Women's Health, 6, 553-558.

Matsubayashi, S., Tamai, H., Matsumoto, Y., Tamagawa, K., Mukuta, T., Morita, T. \& Kubo, C. (1996) Graves' disease after the onset of panic disorder. Psychotherapy and Psychosomatics, 65, 277-280.

Matthews, K.A., Kuller, L.H., Wing, R.R. \& Meilahn, E.N. (1993) Biobehavioral aspects of menopause: lessons from the Healthy Women Study. Experimental Gerontology, 29, 337-342. 
Neugarten, B.L. \& Kraines, R.J. (1965) 'Menopausal symptoms' in women of various ages. Psychosomatic Medicine, 27, 266-273.

Nolan, J.P., Tarsa, N.J. \& DiBenedetto, G. (1985) Case finding for unsuspected thyroid disease: cost and health benefits. American Journal of Clinical Pathology, 83, 346-355.

Overlie, I., Moen, M.H., Skjaeraasen, J.S. \& Holte, A. (1999) The endocrine transition around menopause - a five years prospective study with profiles of gonadotropins, estrogens, androgens and SHBG. Acta Obstetrica et Gynecologica Scandinavica, 78, 642-647.

Paschke, R., Harsch, I., Schlote, B., Vardarli, I., Schaaf, L., Kaumeier, S., Teuber, J. \& Usadel, K.H. (1990) Sequential psychological testing during the course of autoimmune hyperthyroidism. Klinische Wochenschrift, 68, 942-950.

Petersen, K., Lendstedt, G., Lundberg, P., Bengtsson, C., Lapidus, L. \& Hystrom, E. (1991) Thyroid disease in middle-aged and elderly Swedish women: thyroid-related hormones, thyroid dysfunctions and goitre in relation to age and smoking. Journal of Internal Medicine, 22, 407-414.

Prentice, A. (1999) Medical management of menorraghia. British Medical Journal, 319, 1343-1345.

Radloff, L.S. (1977) The CES-D Scale: a self-report depression scale for research in the general population. Applied Psychological Measurement, 1, 385-401.

Samuels, M.H., Veldhuis, J.D., Henry, P. \& Ridgway, E.C. (1990) Pathophysiology of pulsatile and copulsatile release of thyroidstimulating hormone, luteinizing hormone, follicle-stimulating hormone, and $\alpha$-subunit. Journal of Clinical Endocrinology and Metabolism, 71, 425-432.

Sawin, C.T., Hershman, J.M., Boyd, A.E., Longcope, C. \& Bacharach, P. (1978) The relationship of changes in serum estradiol and progeserone during the menstrual cycle to the thyrotropin and prolactin responses to thyrotropin-releasing hormone. Journal of Clinical Endocrinology and Metabology, 47, 1296-1302.

Schectman, J.M., Kallenberg, G.A., Hirsch, R.P. \& Shumacher, R.J. (1991) Report of an association between race and thyroid stimulating hormone level. American Journal of Public Health, 81, 505-506.

Sowers, M.F., Crawford, S., Sternfeld, B., Morgenstein, D., Gold, E.,
Greendale, G., Evans, D., Neer, R., Matthews, K., Sherman, S., Lo, A., Weiss, G. \& Kelsey, J. (2000) Design, survey sampling and recruitment methods of SWAN: a multi-center, multi-ethnic, communitybased cohort study of women and the menopausal transition. In Menopause: Biology and Pathobiology (eds J. Wren, R. A. Lobo, J. Kelsey \& R. Marcus), pp. 175-188. Academic Press, San Diego, CA.

Stern, R.A., Robinson, B., Thorner, A.R., Arruda, J.E., Prohaska, M.L. \& Prange, A.J. Jr (1996) A survey study of neuropsychiatric complaints in patients with Graves' disease. The Journal of Neuropsychiatry and Clinical Neurosciences, 8, 181-185.

Stoffer, S.S. (1982) Menstrual disorders and mild thyroid insufficiency: intriguing cases suggesting an association. Journal of Postgraduate Medicine, 72 (75-7), 80-82.

Tunbridge, W.M.G., Evered, D.C., Hall, R., Appleton, D., Brewis, M., Clark, F., Evans, J.G., Young, E., Bird, T. \& Smith, P.A. (1977) The spectrum of thyroid disease in a community. The Whickham Survey. Clinical Endocrinology, 7, 481-493.

Van den Beld, A., de Jong, F.H., Grobbee, D.E., Pols, H.A.P. \& Lamberts, S.W.J. (2000) Measures of bioavailable serum testosterone and estradiol and their relationships with muscle strength, bone density and body composition in elderly men. Journal of Clinical Endocrinology and Metabolism, 85, 3276-3282.

Vanderpump, M., Tunbridge, W., French, J., Appleton, D., Bates, D., Clark, F., Evans, J., Hasan, D., Rodgers, H., Tunbridge, F. \& Young, E. (1995) The incidence of thyroid disorders in the community: a twentyyear follow-up of the Whickham Survey. Clinical Endocrinology, 43, $55-68$.

Wilansky, D.L. \& Greisman, B. (1989) Early hypothyroidism in patients with menorraghia. American Journal of Obstetrics and Gynecology, 160, 673-677.

Wilson, J.D. \& Foster, D.E. (1985) Williams Textbook of Endocrinology, 7th edn. W. B. Saunders Co., Philadelphia.

Yarwood, N.J., Gurr, J.A., Sheppard, M.C. \& Franklyn, J.A. (1993) Estradiol modulation thyroid hormone regulation of the human glycoprotein hormone $\alpha$ subunit gene. Journal of Biological Chemistry, 268, 21894-21899. 